\title{
Rearview
}

\section{Huawei and goodbye}

\section{A regular column on the information industries}

\section{Peter Curwen}

Peter Curwen is based at Newcastle Business School, Northumbria University, Newcastle upon Tyne, UK.
S ome equipment vendors operate primarily in the market for network infrastructure, some primarily in the smartphone market and a very few are prominent in both. One such is Huawei, based in China. It has recently been attracting a great deal of media attention, almost all of which has been highly negative. This is fundamentally because it is a company without a stock market listing and hence public scrutiny that is widely viewed as a willing agent of the Chinese Government, although the company itself claims that it is one step removed. In essence, what is widely believed is that if the government "requests" its co-operation in passing on consumer or business data or, as many suspect, in spying on other countries, Huawei has little choice but to comply.

Huawei - more strictly the Huawei Technologies Co Ltd - is now part of a trade blacklist created by an executive order signed by President Trump as part of economic sanctions designed to influence the balance of trade between the USA and China. The executive order authorises the Secretary of Commerce to deny access to the USA to companies deemed to be national security threats. Although no specific countries or companies were in initially specified, Huawei was subsequently named on an "Entity List" of blacklisted companies.

But why is Huawei so significant in this regard? Consider, first, the market for hand-held devices, especially smartphones. It is unfortunate that the decision by Apple towards the end of 2018 to discontinue the publication of smartphone shipments means that an element of guesswork has crept into the calculation of shipments and market shares, and there are discrepancies between the data released by the likes of Strategy Analytics and Canalys. However, what seems to be clear is that the overall market for smartphones has been shrinking for the past five quarters, representing the first year-on-year decline since the iPhone first appeared in 2007.

According to telecoms.com, 1,488 million smartphones were shipped in 2016, 1,507 million in 2017 and 1,432 million in 2018, with the quarterly peak of 400 million reached in 2017Q4. Having made their best guess about the Apple shipments data, telecoms. com reckon that there are three dominant vendors: Samsung with market shares in 2016, 2017 and 2018 of 20.6, 21.1 and 20.3 per cent, 
respectively; Apple with 14.5, 14.3 and 14.4 per cent, respectively; and Huawei with 9.3, 10.2 and 14.4 per cent, respectively. Oppo and Xiaomi (both Chinese) have also been making good progress but have yet to break the 10 per cent barrier.

The distinction between Huawei and its two main rivals can be simply expressed: in a declining market, Huawei has built up its shipments from 137 million to 205 million during 2017 and 2018, whereas its rivals ended the period with fewer shipments than at the beginning. On that basis, it would be reasonable to assume that Huawei would have displaced Samsung as the world's largest vendor of smartphones within a couple of years.

A factor worth noting in this regard is that whereas Apple is the exclusive user of iOS, all the other main vendors use Android. Hence, it is much easier for Huawei to displace Samsung than it is to displace Apple. Second, the Chinese market, which is the largest in the world, has provided a massive growth opportunity for the domestic vendors while proving problematic for overseas rivals. On the back of its guaranteed domestic sales, Huawei has been able to push out into foreign markets, including Europe - there are more than three million Huawei smartphones in use in the UK alone - with considerable success. Recently, the Chinese market has been rather weak, thereby encouraging Huawei to substitute export sales for lost domestic sales.

The Trump executive order accordingly has massive implications for Huawei's smartphone business. In May 2019, Google - the owner of Android - responded to the order by stating that it would be obliged to restrict Huawei's access to Android and to Google apps. Initially, while its apps would still work on Huawei smartphones and updates would still be available, these would only be forthcoming via the open-source version of Android rather than the version supported by Google. This would mean a significant delay before security updates and new features could be accessed which would not be the case for Huawei's rivals.

Subsequently, Huawei smartphones would be denied access to the Google Play Store where the majority of users access most of their Android apps. Being deprived of access to the likes of Gmail, YouTube and Google Maps is arguably enough to make Huawei products unsellable anywhere outside China given that, while Huawei smartphones generally receive good reviews, there are plenty of highlyrated alternatives - including iPhones.

It should also be borne in mind that a new version of Android - Android Q is expected to be launched later in 2019. Huawei claim that they can develop their own alternatives to products that will be lost, but presumably not before there has been a major switch by users to other vendors, and the ground lost may well be permanent if people come to believe that Huawei is indeed spying on them. An added disincentive is that Huawei's products are not faulty, so if a smartphone is bought and further issues arise in relation to Android, there is no way for owners to be recompensed. An obvious sign of troubles ahead is that the Huawei P20 Pro - which won awards in 2018 despite a price tag of $£ 800$ in the UK - is now worth a mere $£ 50$ as a trade-in against a new smartphone.

The smartphone market is accordingly about to exhibit a considerable structural change, especially bearing in mind that the other three main Chinese brands including Vivo may well end up being regarded as in the same boat as Huawei. Between them, the four Chinese vendors controlled 38 per cent of the smartphone market at the end of 2018, but how much will be left at the end of 2019, and who will be the main beneficiaries? An obvious beneficiary might seem to be Apple, but it would come as no surprise if Chinese iPhone owners respond by switching to handsets made by Huawei.

The executive order also has ramifications for fixed-wire networks as well as the component makers for smartphones. The order covers designs that contain "US origin technology" which accordingly affects chipmakers Qualcomm and (Japanese-owned) ARM with unpredictable consequences. More crucially, Huawei has been excluded from constructing any part of the newly emerging so-called " $5 \mathrm{G}$ " networks in the USA even though it has invested massively in developing $5 \mathrm{G}$ architecture and is widely considered to be the world leader in the technology.

Not surprisingly, several countries that prefer to retain a close relationship with the USA, such as Australia and Japan, have followed its example and blacklisted Huawei. Others, particularly in the EU, have preferred on principle to refuse to toe the US line, whereas yet others such as the UK have remained neutral that is, prepared to accept Huawei products provided they can be thoroughly inspected in advance for software that could enable spyware to be activated.

The consequence for countries denying contracts to Huawei is that they will have to rely on network vendors with inferior products, which will hold back the development of 5G. The extent to which this matters is difficult to assess for now, but there can be no doubt that in a year or two the market shares of network equipment and smartphone vendors may look considerably different from how they stood at the end of 2018 unless, of course - the executive order is rescinded.

\section{Corresponding author}

Peter Curwen can be contacted at: pjcurwen@hotmail.com 